\title{
Financiamento, bem-estar financeiro e qualidade de vida: Percepções dos beneficiários do Pronaf
}

Kelmara Mendes Vieira, Solei Rejane Lenz e Monize Sâmara Visentini

PALAVRAS-CHAVE: crédito, política pública, agricultura familiar, propriedades rurais.

\author{
CLASSIFICAÇÃO JEL: C38, J43, O13, O29.
}

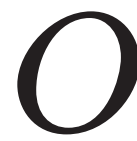

estudo teve como objetivo identificar a percepção do financiamento, do bemestar financeiro e da qualidade de vida dos beneficiários do Programa $\mathrm{Na}$ cional de Fortalecimento da Agricultura Familiar (Pronaf). Para isso, realizou-se uma pesquisa quantitativa, por meio de uma survey, sendo investigados 263 beneficiários do programa distribuídos em 25 municípios do estado do Rio Grande do Sul. A análise dos dados se deu por meio da estatística descritiva e análise de cluster. Os principais resultados apontam que o Pronaf na região estudada tem sido capaz de melhorar as condições produtivas das familias e de qualidade de vida, excetuando-se alguns aspectos do domínio ambiental que ainda precisam ser melhorados. Por outro lado, o nível de bem-estar financeiro destas familias é intermediário, e medidas estratégicas deveriam ser pensadas. Dos três clusters formados, o com menor número de beneficiários é composto por aqueles com as piores percepções de qualidade de vida e de bem-estar financeiro, que gastam igual ou mais do que ganham e possuem mais baixo nível educacional e menores rendas. Ao passo que no cluster com melhor qualidade de vida, observa-se maior percentual de integrantes com maiores níveis de renda, de educação, mais acesso ao cartão de crédito e maior satisfação com a situação financeira. 


\title{
Financing, financial well-being, and quality of life: Perceptions of Pronaf beneficiaries
}

\section{KEYWORDS: credit, public policy, family farming, rural properties.}

\author{
JEL CODES: C38, J43, O13, 029.
}

he study aimed to identify the perception of financing, financial well-being,
and quality of life of the beneficiaries of the National Program for Strength-
ening of Family Agriculture (Pronaf). For that, quantitative research was carried out, through a survey, investigating 263 beneficiaries of the program were investigated, distributed in 25 municipalities in the state of Rio Grande do Sul. The data analysis was done through descriptive statistics and cluster analysis. The main results indicate that Pronaf in the studied region has been able to improve the productive conditions of families and quality of life, except for some aspects of the environmental domain that still need to be improved. On the other hand, the level of the financial wellbeing of these families is intermediate and strategic measures should be considered. Of the three clusters formed, the one with the lowest number of beneficiaries is composed of those with the worst perceptions of quality of life and financial well-being, who spend the same or more than they earn and have the lowest educational level and lowest income. While in the cluster with a better quality of life, a higher percentage of members with higher levels of income, education, more access to credit cards, and greater satisfaction with the financial situation is observed.

Recepção: 2020-04-02 - Revisão: 2020-08-06 - Aceitação: 2020-09-04

Kelmara Mendes Vieira [orcid.org/0000-0002-8847-0941] é professora associada da Universidade $\mathrm{Fe}-$ deral de Santa Maria e atua no Programa de Pós Graduação em Administração Pública da Universidade Federal de Santa Maria-RS. Endereço: Av. Evaldo Behr, 45, Bairro Camobi, 97110-801 Santa Maria-RS (Brasil).E-mail:profkelmara@gmail.com

Solei Rejane Lenz [orcid.org/ 0000-0002-7252-7632] é mestre pelo Programa Profissional em Gestão de Organizações Públicas da Universidade Federal de Santa Maria-RS. Endereço: Av. Facob Reinaldo Haupenthal, 1580, Bairro São Pedro, 97900-000 Cerro Largo-RS (Brasil).E-mail: soleilenz@uffs.edu.br

Monize Sâmara Visentini [orcid.org/0000-0001-6233-6106] é professora do Programa de pós-graduação em Desenvolvimento e Políticas Públicas, Universidade Federal da Fronteira Sul, Cerro Largo-RS. Endereço: Av. Facob Reinaldo Haupenthal, 1580, Bairro São Pedro, 97900-000 Cerro Largo-RS (Brasil). E-mail:monize.visentini@uffs.edu.br 


\section{INTRODUÇÃO}

A busca do bem-estar social, a redução da pobreza e a promoção do desenvolvimento têm ocupado a pauta das políticas públicas no Brasil, principalmente a partir da década de 1970 (Lobato, 2016), motivando a elaboração de projetos e de programas que visam fortalecer os segmentos mais vulneráveis da população. A agricultura sempre teve papel fundamental para o desenvolvimento do país, sendo o agronegócio um dos setores exponenciais.

No decorrer da história do Brasil, basicamente, a política agrícola estimulava primeiramente os grandes e médios produtores, espacialmente localizados na região Sul e Sudeste e com produções destinadas à exportação. Entretanto, com a Constituição Federal de 1988, a partir das reivindicações de movimentos sociais ligados ao campo, tem-se o despontar da expressão e da ação da agricultura familiar. Assim, a partir da década de 1990, ocorre a modificação parcial das prioridades de atuação dos mecanismos de análise das políticas públicas de investimento voltadas ao meio rural e aos agricultores familiares, parcela excluída do processo de modernização, que ocorreu entre as décadas de 1960 e 1980, os quais passaram a ser objeto de política de crédito rural (Silva \& Bernardes, 2014).

Em 1993, para atender a reivindicação dos movimentos sociais, o Ministério da Agricultura e do Abastecimento criou o Programa de Valorização da Pequena Produção Rural (Provap), o qual consistia em uma linha de crédito com critérios de acesso restritos aos agricultores familiares, os quais eram classificados a partir do tamanho do estabelecimento e da mão de obra utilizada na produção (Silva, 1999). Entretanto, complementa Silva (1999: 5), «O PROVAP teve reduzido alcance, sobretudo por causa das rigorosas exigências impostas pelas instituições financeiras ao público-alvo».

A agricultura familiar apenas se consolidou no país, com a criação, em 1996, do Programa Nacional de Fortalecimento da Agricultura Familiar (Pronaf), que proporciona aos agricultores familiares o acesso ao crédito agrícola e ao apoio institucional para o exercício de suas atividades (Schneider, 2003). O Pronaf, ao direcionar suas linhas de crédito a um público marcado pela renegação das políticas públicas, confirmou o reconhecimento e a legitimação do Estado em relação às especificidades de uma nova categoria social os agricultores familiares (Schneider, Cazella \& Mattei, 2004).

Ao longo dos anos, o Pronaf se tornou uma das principais políticas públicas de desenvolvimento agrícola para pequenas propriedades rurais em todo país, incorporando «objetivos ambiciosos e abrangentes» (Zani \& Costa, 2014: 899), como aumento da ca- 
pacidade produtiva, geração de emprego e renda e melhoria da qualidade de vida dos agricultores familiares (Zani \& Costa, 2014; Silva \& Bernardes, 2014), e atuando em diversas linhas de financiamento. O programa proporciona financiamento para custeio e investimentos em implantação, ampliação ou modernização da estrutura de produção, de beneficiamento, de industrialização e de serviços no estabelecimento rural ou em áreas comunitárias rurais próximas, visando à geração de renda e à melhora do uso da mão de obra familiar (BNDES, 2020).

Além das formas convencionais de financiamento, que variam de acordo com o limite financiado e a taxa de juros praticada, algumas linhas específicas de crédito são oferecidas. Tais subprogramas do Pronaf apresentam características próprias, de acordo com o que pode ser financiado, para quem se destina e as especificidades do agricultor familiar. Alguns exemplos são o Pronaf Jovem, o Pronaf Mais Alimentos, o Pronaf Mulher, o Pronaf Agroindústria, o Pronaf Agroecologia e o Pronaf Eco (BNDES, 2020).

Políticas públicas como essa, que concedem recursos financeiros diretamente para o beneficiário -sendo ele responsável pela decisão de como utilizar o recurso- ficam sujeitas à sua capacidade de gerenciamento financeiro. Portanto, entender como os beneficiários planejam, executam e controlam seus recursos é fundamental para conhecer e avaliar a sua aplicação, segundo os objetivos do programa, o que poderá influenciar na melhoria ou não do bem-estar financeiro dessas famílias e impactar diretamente na sua qualidade de vida.

Entende-se como bem-estar financeiro o sentimento de estar financeiramente saudável, sem preocupações monetárias, com base na percepção de sua situação financeira (Joo, 2008). Miranda e Gomes (2016) apontam que o programa contribuiu para o desenvolvimento rural sustentável ao elevar a renda, fortalecer a capacidade produtiva da agricultura familiar e estimular a manutenção local da atividade agrícola de pequena escala. Assim, supõe-se que a correta decisão e aplicação dos recursos oriundos do Pronaf podem ampliar a sensação de bem-estar financeiro do seu beneficiário. Também, pessoas satisfeitas financeiramente acabam sendo mais felizes nos demais aspectos da vida (Plagnol, 2011). Nesse sentido, Castro e Campos (2010) identificaram que, em termos de indicadores, em média houve melhoria nos índices do nível de qualidade de vida dos beneficiários do Pronaf.

Tais constatações indicam que o modo como são geridos os recursos do programa tendem a acarretar consequências em fatores comportamentais do beneficiário, instigando esta pesquisa, que visa identificar a percepção do financiamento, do bem-estar financeiro e da qualidade de vida dos beneficiários do Pronaf. A partir desta constatação, procura- 
se, como objetivo secundário, estabelecer subgrupos de beneficiários que contenham perfis semelhantes de percepção de bem-estar financeiro e qualidade de vida, por meio de clusters.

Deve-se observar que o Pronaf, como parte de uma política pública para o desenvolvimento rural, é responsável por grandes mudanças na agricultura nacional e, assim, necessita da avaliação de seus resultados, como forma de garantir que esteja cumprindo com os objetivos de incentivar e de proteger a parcela da população rural que tem forte participação na economia do país. Ao se analisar os efeitos de uma política pública na visão do usuário final, neste caso, em especial, quanto ao seu bem-estar financeiro e qualidade de vida, pode-se melhor compreender os resultados da aplicação dessa política no comportamento do beneficiário.

Tendo em vista as constantes alterações que ocorrem, tanto na política quanto na economia do país, e sabendo-se que o beneficiário tem a liberdade de decisão sobre a alocação dos recursos provenientes do Pronaf, os resultados efetivos da concessão dependem em grande parte da forma de utilização desses recursos. Nesse contexto, implementar programas de formação para os agricultores e incentivar a educação gerencial de forma a favorecer o desenvolvimento da capacidade de gestão e de avaliação dos resultados da alocação de recursos (Tomei \& Souza, 2014) são ações que podem contribuir para a melhoria na utilização final do recurso e, consequentemente, aumentar a eficiência da política pública. Os achados desta investigação tendem a apontar a necessidade da condução dessas ações pelos órgãos públicos envolvidos diretamente no programa.

\section{O PROGRAMA NACIONAL DE FORTALECIMENTO DA AGRICULTURA FAMILIAR (PRONAF)}

No Brasil, a institucionalização de uma política agrícola articulada ocorre com a criação do Sistema Nacional de Crédito Rural (SNRC) no ano de 1965, no qual a concessão de crédito rural subsidiado era o principal instrumento utilizado para a implementação do projeto de modernização da agricultura brasileira. Tal programa vigorou até o início da década de 1980, quando o Brasil e os países da América Latina foram duramente atingidos por uma forte crise e isso reduziu drasticamente os investimentos agrícolas (Saron \& Hespanhol, 2012). Ao priorizar a concessão de créditos para os grandes e médios proprietários produtores de comodities localizados na porção Centro-Sul do Brasil, tal política foi muito negativa para a produção de base familiar, realizada em pequena escala (Hespanhol, 1997). 
A partir da abertura política, organizações nacionais como a Confederação Nacional dos Trabalhadores na Agricultura (CONTAG), a do Movimento dos Trabalhadores Rurais Sem Terra (MST), a da Confederação Nacional dos Bispos do Brasil (CNBB), e as organizações internacionais como o Banco Internacional de Reconstrução e Desenvolvimento (BIRD) e estudos realizados pela Fundação das Nações Unidas para Agricultura e Alimentação e Instituto Nacional de Colonização e Reforma Agrária passam a pressionar para a criação de uma política especial voltada especificamente à agricultura familiar (Schneider, Cazella \& Mattei, 2004; Neves, 2007).

Assim, o Pronaf foi criado pela Resolução n. ${ }^{\circ}$ 2.191, de 24 de agosto de 1995, do Banco Central do Brasil, com foco na concessão de crédito de custeio e investimento para a atividade produtiva familiar. No ano seguinte, foi oficializado através do Decreto da Presidência da República n. ${ }^{\circ} 1.946$, de 28 de junho de 1996, com o objetivo de «promover o desenvolvimento sustentável do segmento rural constituído pelos agricultores familiares, de modo a propiciar-lhes o aumento da capacidade produtiva, a geração de emprego e melhoria de renda».

Os créditos podem ser concedidos de forma individual ou coletiva, sendo considerado crédito coletivo quando formalizado por grupo de produtores para finalidades coletivas. Para serem considerados beneficiários do programa, os agricultores e produtores rurais devem compor unidades familiares de produção rural e comprovar seu enquadramento mediante apresentação da «Declaração de Aptidão ao Pronaf (DAP)» ativa (Ministério Do Desenvolvimento Agrário, 2014).

A finalidade dos créditos de custeio está relacionada às atividades ligadas à produção em todas as suas fases, à entressafra e à agregação de valor, armazenamento e comercialização de produtos agropecuários produzidos em unidades de produção familiar. Já os créditos de investimentos são destinados às operações com o objetivo de ampliar e modernizar o processamento da unidade de produção familiar. Há também o incentivo a atividades relacionadas à comercialização da produção, ao turismo, à preservação do meio ambiente, ao extrativismo e à melhoria da infraestrutura geral (Pires, 2013).

O Pronaf possui, além das formas convencionais de financiamento, que variam de acordo com o limite financiado e a taxa de juros praticada, algumas linhas específicas de crédito, com características próprias, conforme detalhado no Quadro 1.

O Pronaf possibilitou o reconhecimento da importância do pequeno agricultor, proporcionando-lhe um espaço de trabalho mais digno e sustentável (Santos et al., 2012). 


\section{QUADRO 1}

Subprogramas do Pronaf e suas características

Subprogramas

Pronaf Custeio

Pronaf Investimento

1995-1996

Pronaf Agroindústria

2004-2005

Pronaf Mulher

2004-2005

Pronaf Agroecologia

2004-2005

Pronaf Florestal

2002-2003

Pronaf Eco

2007-2008

Pronaf Semiárido

Pronaf Mais Alimentos

2008-2009

Pronaf Jovem

2004-2005

Pronaf Microcrédito (Grupo B)

Pronaf Cotas-Partes

2004-2005

Pronaf Crédito Fundiário Proagro

1998

2004

Seguro Vida AF

2013-2014 Características

Crédito para financiamento das atividades agropecuárias, de beneficiamento ou industrialização e comercialização da produção.

Destinado ao financiamento da implantação, ampliação ou modernização da infraestrutura de produção e serviços, agropecuários ou não, no estabelecimento rural ou em áreas comunitárias rurais próximas.

Financiamento a agricultores e produtores rurais familiares, pessoas físicas e jurídicas, e a cooperativas para investimento em beneficiamento, armazenagem, processamento e comercialização agrícola, extrativista, artesanal e de produtos florestais e para apoio à exploração de turismo rural.

Financiamento à mulher agricultora integrante de unidade familiar de produção enquadrada no Pronaf, independentemente do estado civil.

Financiamento a agricultores e produtores rurais familiares, pessoas físicas, para investimento em sistemas de produção agroecológicos ou orgânicos, incluindo-se os custos relativos à implantação e manutenção do empreendimento.

Crédito para investimento em sistemas agroflorestais, exploração extrativista ecologicamente sustentável, plano de manejo e manejo florestal, recomposição e manutenção de áreas de preservação permanente e reserva legal e recuperação de áreas degradadas, enriquecimento de áreas que já apresentam cobertura florestal diversificada.

Financiamento a agricultores e produtores rurais familiares, pessoas físicas, para investimento na utilização de tecnologias de energia renovável, tecnologias ambientais, armazenamento hídrico, pequenos aproveitamentos hidroenergéticos, silvicultura e adoção de práticas conservacionistas e de correção da acidez e fertilidade do solo, visando à sua recuperação e melhoramento da capacidade produtiva. Crédito para implantar, utilizar, recuperar ou adotar tecnologias de energia renovável. Pronaf ECO Silvicultura, Dendê e Seringueira-Crédito para implantação de viveiros florestais e das culturas do dendê ou da seringueira. Crédito de investimento em projetos de infraestrutura hídrica e implantação, ampliação, recuperação ou modernização das demais infraestruturas, agropecuárias e não agropecuárias, na região do semiárido.

Financiamento a agricultores e produtores rurais familiares, pessoas físicas, para investimento em sua estrutura de produção e serviços, visando ao aumento de produtividade e à elevação da renda da família.

Financiamento a agricultores e produtores rurais familiares, pessoas físicas, para investimento nas atividades de produção, desde que beneficiários sejam maiores de 16 anos e menores de 29 anos, entre outros requisitos.

Financiamento a agricultores e produtores rurais familiares, pessoas físicas, que tenham obtido renda bruta familiar de até $\mathrm{R} \$ 20.000$, nos 12 meses de produção normal que antecederam à solicitação da Declaração de Aptidão (DAP) ao Pronaf. Crédito para investir na implantação, ampliação e modernização da infraestrutura de produção e serviços, no estabelecimento rural ou em áreas comunitárias rurais próximas.

Financiamento para integralização de cotas-partes por beneficiários do Pronaf associados às cooperativas de produção rural; aplicação, pela cooperativa, em capital de giro, custeio, investimento ou saneamento financeiro.

Crédito para aquisição de terras e implantação inicial da atividade agropecuária. Proteção quando da ocorrência de sinistro na lavoura agrícola. 0 Programa de Garantia da Atividade Agropecuária (Proagro) tem por objetivos exonerar 0 beneficiário do cumprimento de obrigações financeiras em operações de crédito rural de custeio, no caso de perdas das receitas, e indenizar os recursos próprios do beneficiário, utilizados em custeio rural, inclusive em empreendimento não financiado, no caso de perdas das receitas em consequência de sinistro na lavoura.

Fonte: elaborado a partir de dados do Ministério Do Desenvolvimento Agrário (2018).

Historia Agraria, 84 - Agosto 2021 • pp. 209-238 
Bianchini (2015) destaca que, nos 20 anos desde sua criação, o programa esteve presente em todos os municípios rurais do território brasileiro, dispondo de mais de $\mathrm{R} \$ 150$ bilhões para mais de dois milhões de famílias.

Assim, desde a sua criação, o Pronaf tem proporcionado para a agricultura familiar avanços como a ampliação da oferta de recursos, a ampliação dos beneficiários e a expansão para outras regiões. Entretanto, ainda se questiona se o programa continua fazendo «mais do mesmo» (segue incentivando o modelo de desenvolvimento do período de modernização da agricultura) e "mais com os mesmos» (o apoio aos agricultores familiares já com maior familiaridade com o sistema bancário, ainda que também alijados das políticas de modernização da agricultura nas décadas de 1960-1970) (Grisa, Wesz Junior \& Buchweitz, 2014).

Neste sentido, Troian e Machado (2020) afirmam que os desafios atuais para o Pronaf são: 1) diminuição da desigualdade da distribuição do crédito; 2) busca de métodos não excludentes no auxílio a pequena propriedade; 3 ) adaptação do programa à pluralidade regional dos agricultores familiares em suas diferentes realidades; 4) promoção, em maior magnitude, da diversificação da produção e das fontes de rendimento; e 5) extinção da prática seletiva dos bancos, assim, beneficiando os diversos segmentos de agricultores familiares.

\section{BEM-ESTAR FINANCEIRO E QUALIDADE DE VIDA NO ÂMBITO DO PRONAF}

O Pronaf é o principal programa entre as políticas públicas de incentivo à agricultura e promoção de seu desenvolvimento. Isso se comprova na medida em que facilita a inserção dos agricultores familiares no mercado do agronegócio, aumenta a geração de renda e agrega valor ao produto e à propriedade por meio da modernização dos sistemas produtivos e da profissionalização desses produtores (Bianchini, 2015).

Para uma eficaz alocação dos recursos do programa, é fundamental a gestão financeira adequada, pois sua ausência maximiza hábitos de consumo impulsivos, práticas orçamentárias disfuncionais ou ruins e consequências financeiras e pessoais graves, tais como endividamento, problemas de saúde e estresse emocional (Chen, Gu \& Chen, 2012). Para evitar tais riscos, cabe ao beneficiário ter consciência da sua situação financeira pessoal (Delafrooz \& Paim, 2011), estando atento às condições presentes e futuras, características vinculadas ao conceito de bem-estar financeiro (Malone et al., 2010; Chan, Chau \& Chan, 2012). A visão atual envolve os rendimentos mensais, como forma de atender ne- 
cessidades imediatas, e a futura representa as perspectivas e interesses de cada indivíduo para períodos posteriores (Norvilitis, Szablicki \& Wilson, 2003).

No sentido de compreender características da aplicação dos recursos e do bem-estar financeiro de beneficiários do programa, Mello, Silveira e Silva (2017) avaliaram os efeitos do Pronaf na vida das mulheres do estado de Minas Gerais. A maioria delas associou o crédito a um aumento da renda própria e oportunidade de ampliar as atividades de sua propriedade. Essa autonomia e capacidade para fazer escolhas promovem o empoderamento feminino e demonstram que, quando podem administrar seus próprios recursos, as mulheres contribuem de forma mais eficaz para o bem-estar da família. Também no contexto mineiro, Sena et al. (2011) analisaram a utilização de ferramentas de planejamento e controle na gestão dos recursos advindos do Pronaf por parte dos agricultores familiares das Associações Comunitárias do Vale do Bananal, no município de Salinas. Identificaram que tanto os associados quanto a maioria dos presidentes das associações realizam algum tipo de planejamento e controle, possibilitando a essas pessoas anteciparse a novas situações ou problemas e melhor aproveitar os recursos disponíveis. Entretanto, conforme ressaltado pelos autores, não há um assessoramento ao agricultor, por parte das associações, no planejamento e acompanhamento do projeto a ser executado.

Também a título de avaliação do bem-estar financeiro, o Consumer Financial Protection Bureau (CFPB, 2015) desenvolveu uma das escalas mais recentes sobre o tema, que permite aos profissionais e pesquisadores quantificar com precisão e consistência esse construto, a partir de dez itens. No Brasil, esta escala e/ou adaptações dela já foram replicadas, por exemplo, por Kunkel, Vieira e Potrich (2015), Campara eVieira (2016) e Santos et al. (2016). Extensões dessa escala já foram desenvolvidas, sendo uma delas apresentada pela Organisation for Economic Co-Operation and Development (OECD, 2018). Até o momento, não se tem conhecimento da aplicação de nenhuma dessas duas escalas no contexto de avaliação dos beneficiários do Pronaf, para além desta investigação.

Binder e Coad (2015) destacam que boas condições financeiras, tanto no presente quanto no futuro, incluída a segurança monetária, maximizam o bem-estar financeiro e proporcionam melhor qualidade de vida. O conceito é variável de uma pessoa para outra (World Health Organization Quality of Life) (WHOQOL Group, 1994), sendo a sua percepção dependente de diversos fatores, que englobam aspectos culturais e socioeconômicos, políticas públicas, relacionamento com o trabalho, educação, o indivíduo e seus valores, expectativas e preocupações. Aleixo et al. (2007), ao avaliar os indicadores de qualidade de vida de beneficiários do Pronaf em assentamentos de reforma agrária na região Nordeste, concluiu que ocorreu melhora após a implementação do programa, em especial no que se refere ao acesso aos bens de consumo duráveis e às condições de moradia. 
Diante da necessidade de avaliação das políticas públicas, é importante analisar os efeitos e as mudanças que podem vir a ocorrer na qualidade de vida das pessoas atingidas. Para acompanhar e avaliar essas mudanças, a WHOQOL (1997) desenvolveu um projeto colaborativo internacional e multicêntrico de iniciativa da Organização Mundial de Saúde (OMS), resultando em um instrumento aplicável a várias populações, com diferentes realidades socioculturais. O primeiro a ser criado foi o WHOQOL 100; posteriormente, surgiu a versão abreviada ou WHOQOL-BREF já traduzido para o português e composto por 26 questões (Fleck et al., 2010).

No âmbito do Pronaf Jovem, uma categoria para estimular a permanência dos jovens no meio rural, Gouveia (2010) aplicou a escala reduzida para verificar os impactos na qualidade de vida de agricultores paraibanos. Os resultados indicaram índices satisfatórios de qualidade de vida, e o programa foi avaliado positivamente pelos beneficiários, que apontaram melhorias nas suas condições de vida e de trabalho.

\section{MÉTODO}

Com a finalidade de atingir os objetivos propostos, adotou-se uma pesquisa de caráter descritivo, baseada em uma abordagem quantitativa. A coleta de dados foi realizada por meio de uma pesquisa survey, para a qual foi elaborado um instrumento de pesquisa com quatro blocos de questões, distribuídas conforme o Quadro 2.

\section{QUADRO 2}

\section{Descrição do instrumento de pesquisa}

\begin{tabular}{lll}
\hline Bloco de questões & Questões & Referências \\
\hline Perfil dos entrevistados & 14 questões & Elaborado pelas autoras \\
Características do programa contratado & 14 questões & Elaborado pelas autoras, \\
e de produção das propriedades & & baseando-se em BNDES (2020) \\
Bem-estar financeiro & 10 questões & OECD (2018) \\
Qualidade de vida & 26 questões & Gouveia (2010) \\
\hline
\end{tabular}

Fonte: elaborado pelas autoras.

No bloco I são apresentadas as questões referentes ao perfil sociodemográfico, financeiro e de moradia dos entrevistados. O bloco II refere-se às características do Pronaf contratado, bem como das unidades produtivas das propriedades rurais. No bloco III são dez questões de bem-estar financeiro (Apêndice A), apresentadas no instrumento desenvolvido pela OECD (2018), o qual compreende cinco perguntas da escala da CFPB (2015) e cinco perguntas específicas. Por fim, no bloco IV, introduz-se a escala de qualidade de 
TABELA 1

Questões, domínios, categorias e estatísticas descritivas das questões relativas as escalas de qualidade de vida e bem-estar financeiro

\begin{tabular}{|c|c|c|c|c|}
\hline Questões & Domínio & Categorias & Média & $\begin{array}{l}\text { Desvio } \\
\text { padrão }\end{array}$ \\
\hline \multicolumn{5}{|l|}{ Qualidade de vida } \\
\hline 1. Como você avaliaria sua qualidade de vida? & Geral & $\begin{array}{l}1 \text { (muito ruim) } \\
5 \text { (muito boa) }\end{array}$ & 3,84 & 0,56 \\
\hline 2. Quão satisfeito(a) você está com a sua saúde? & Geral & $\begin{array}{l}1 \text { (muito insatisfeito) } \\
5 \text { (muito satisfeito) }\end{array}$ & 3,71 & 0,65 \\
\hline $\begin{array}{l}\text { 3. Em que medida você acha que sua dor (física) } \\
\text { impede você de fazer o que você precisa?*}\end{array}$ & Físico & $\begin{array}{l}1 \text { (nada) } \\
5 \text { (extremamente) }\end{array}$ & 3,57 & 0,45 \\
\hline $\begin{array}{l}\text { 4. } 0 \text { quanto você precisa de algum tratamento } \\
\text { médico para levar sua vida diária?*}\end{array}$ & Físico & & 3,82 & 1,01 \\
\hline 5. 0 quanto você aproveita a vida? & Psicológico & & 3,38 & 0,66 \\
\hline 6. Em que medida você acha que a sua vida tem sentido? & Psicológico & & 3,87 & 0,68 \\
\hline 7. 0 quanto você consegue se concentrar? & Psicológico & & 3,51 & 0,69 \\
\hline 8. Quão seguro(a) você se sente em sua vida diária? & Ambiental & & 3,61 & 0,65 \\
\hline $\begin{array}{l}\text { 9. Quão saudável é o seu ambiente físico } \\
\text { (clima, barulho, poluição, atrativos)? }\end{array}$ & Ambiental & & 3,47 & 0,76 \\
\hline 10. Você tem energia suficiente para seu dia a-dia? & Físico & $\begin{array}{l}1 \text { (nada) } \\
5 \text { (completamente) }\end{array}$ & 3,66 & 0,71 \\
\hline 11. Você é capaz de aceitar sua aparência física? & Psicológico & & 3,90 & 0,80 \\
\hline $\begin{array}{l}\text { 12. Você tem dinheiro suficiente para satisfazer } \\
\text { suas necessidades? }\end{array}$ & Ambiental & & 3,28 & 0,73 \\
\hline $\begin{array}{l}\text { 13. Quão disponíveis para você estão as informações } \\
\text { que precisa no seu dia a dia? }\end{array}$ & Ambiental & & 3,41 & 0,65 \\
\hline $\begin{array}{l}\text { 14. Em que medida você tem oportunidades } \\
\text { de atividade de lazer? }\end{array}$ & Ambiental & & 3,08 & 0,79 \\
\hline 15. Quão bem você é capaz de se locomover? & Físico & $\begin{array}{l}1 \text { (muito ruim) } \\
5 \text { (muito bom) }\end{array}$ & 4,10 & 0,58 \\
\hline 16. Quão satisfeito(a) você está com o seu sono? & Físico & $\begin{array}{l}1 \text { (muito insatisfeito) } \\
5 \text { (muito satisfeito) }\end{array}$ & 3,81 & 0,75 \\
\hline $\begin{array}{l}\text { 17. Quão satisfeito(a) você está com sua capacidade de } \\
\text { desempenhar as atividades do seu dia a dia? }\end{array}$ & Físico & & 3,88 & 0,60 \\
\hline $\begin{array}{l}\text { 18. Quão satisfeito(a) você está com sua capacidade } \\
\text { para o trabalho? }\end{array}$ & Físico & & 3,87 & 0,65 \\
\hline 19. Quão satisfeito(a) você está consigo mesmo? & Psicológico & & 3,97 & 0,54 \\
\hline $\begin{array}{l}\text { 20. Quão satisfeito(a) você está com suas relações } \\
\text { pessoais (amigos, parentes, conhecidos, colegas)? }\end{array}$ & Relações sociais & & 4,01 & 0,55 \\
\hline 21. Quão satisfeito(a) você está com sua vida sexual? & Relacões sociais & & 3,96 & 0,55 \\
\hline $\begin{array}{l}\text { 22. Quão satisfeito(a) você está com o apoio que você } \\
\text { recebe de seus amigos? }\end{array}$ & Relações sociais & & 3,91 & 0,52 \\
\hline $\begin{array}{l}\text { 23. Quão satisfeito(a) você está com as condições } \\
\text { do local onde mora? }\end{array}$ & Ambiental & & 4,03 & 0,57 \\
\hline $\begin{array}{l}\text { 24. Quão satisfeito(a) você está com o seu acesso } \\
\text { aos serviços de saúde? }\end{array}$ & Ambiental & & 3,55 & 0,78 \\
\hline $\begin{array}{l}\text { 25. Quão satisfeito(a) você está com o seu meio } \\
\text { de transporte? }\end{array}$ & Ambiental & & 3,89 & 0,64 \\
\hline $\begin{array}{l}\text { 26. Com que frequência você tem sentimentos negativos } \\
\text { tais como mau-humor, desespero, ansiedade, depressão? }\end{array}$ & Psicológico & 1 (sempre)-5 (nunca) & 4,12 & 0,73 \\
\hline
\end{tabular}




\begin{tabular}{|c|c|c|c|c|}
\hline Questões & Domínio & Categorias & Média & $\begin{array}{l}\text { Desvio } \\
\text { padrão }\end{array}$ \\
\hline \multicolumn{5}{|l|}{ Bem-estar financeiro } \\
\hline 27. Estou satisfeito(a) com minha atual situação & Bem-estar financeiro & 1 (discordo totalmente) & 3,48 & 0,87 \\
\hline financeira. & & \multicolumn{3}{|l|}{5 (concordo totalmente) } \\
\hline $\begin{array}{l}\text { 28. Minha situação financeira limita minha capacidade de } \\
\text { fazer as coisas que são importantes para mim. * }\end{array}$ & Bem-estar financeiro & & 2,88 & 0,94 \\
\hline 29. Neste momento, eu possuo muitas dívidas. ${ }^{*}$ & Bem-estar financeiro & & 3,46 & 1,06 \\
\hline 30. Eu tenho a tendência de viver hoje e deixar & Bem-estar financeiro & 1 (completamente) & 4,32 & 1,04 \\
\hline 0 amanhã cuidar de si. & & \multicolumn{3}{|l|}{5 (de modo nenhum) } \\
\hline $\begin{array}{l}\text { 31. Por causa da minha situação financeira, sinto que } \\
\text { nunca terei as coisas que quero na minha vida. }\end{array}$ & Bem-estar financeiro & & 3,87 & 0,99 \\
\hline 32. Estou preocupado(a) que o meu dinheiro não vai durar & Bem-estar financeiro & & 3,43 & 0,98 \\
\hline 33. Eu estou apenas sobrevivendo financeiramente. & Bem-estar financeiro & & 3,50 & 1,14 \\
\hline $\begin{array}{l}\text { 34. Eu tenho a tendência de me preocupar em pagar } \\
\text { minhas despesas do dia a dia. }\end{array}$ & Bem-estar financeiro & & 1,42 & 0,76 \\
\hline 35. Minhas finanças controlam minha vida. & Bem-estar financeiro & & 2,54 & 1,01 \\
\hline 36. Eu tenho dinheiro sobrando no fim do mês. * & Bem-estar financeiro & & 2,98 & 0,86 \\
\hline
\end{tabular}

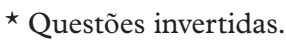

Fonte: dados da pesquisa (2020).

vida proposta pela WHOQOL e aplicada previamente no contexto do Pronaf por Gouveia (2010), constituída de 26 perguntas, sendo duas perguntas sobre a qualidade de vida geral e as demais referentes aos quatros domínios da escala: físico (7 questões), psicológico (6 questões), relações socais (3 questões) e ambiental, referente ao meio ambiente onde o indivíduo está inserido (8 questões). Para ambas as escalas dos blocos III e IV foram utilizadas questões de múltiplas escolhas e escalas tipo Likert de cinco pontos. Para o cômputo dos domínios da escala, seguiu-se a metodologia proposta por Harper e Power (2013), conforme detalhado no Apêndice A. A Tabela 1 apresenta as questões e categorias das escalas dos blocos III e IV do instrumento, bem como as médias e desviospadrões.

Previamente à aplicação, o instrumento foi submetido à avaliação por três especialistas e foi realizado um pré-teste com cinco beneficiários com o objetivo de avaliar a adequação semântica e de conteúdo do instrumento. A aplicação do instrumento ocorreu em visitas às propriedades dos beneficiários e em encontros das cooperativas e associações rurais dos municípios. A pesquisa foi aprovada pelo Comitê de Ética em Pesquisa (Certificado de Apresentação para Apreciação Ética-CAAE 10663219.7.0000.5346). 
A população alvo do estudo compreendeu os beneficiários do Pronaf, na região de abrangência do Conselho Regional de Desenvolvimento-Corede Missões. O Corede Missões está localizado na fronteira do Brasil com a Argentina, sendo formado por $25 \mathrm{mu}-$ nicípios e possuindo uma base econômica mais voltada à agropecuária em relação à média do Rio Grande do Sul, com pouca participação da indústria. Segundo dados do crédito rural do Banco Central do Brasil (BCB, 2017) na região, foram concedidos 13.560 financiamentos Pronaf (custeio e investimento) no período de 2017, perfazendo um montante de $\mathbf{R} \$ 325.550 .235,60$.

No processo de amostragem considerou-se um erro amostral de $6 \%$, com $95 \%$ de confiança e uma população finita de 13.560 beneficiários, compondo uma amostra final de 263 beneficiários distribuídos proporcionalmente ao número de contratos entre os $25 \mathrm{mu}$ nicípios do Corede.

$\mathrm{Na}$ análise dos resultados, inicialmente realizou-se uma análise descritiva das variáveis dos quatro blocos apresentados no Quadro 2. Na sequência, utilizou-se a análise de cluster, tendo como objetivo agregar os entrevistados com base nas suas características (Hair et al., 2010). De acordo com Malhotra (2011), os conglomerados obtidos devem apresentar tanto uma homogeneidade interna (dentro de cada conglomerado), assim como heterogeneidade externa (entre conglomerados), diferenciando-se dos demais. Como método de aglomeração foi utilizado o Ward, também denominado método da variância. $\mathrm{O}$ método de Ward foi selecionado por ser um dos mais consistentes para escalas intervalares (Hair et al., 2010). Ressalta-se que para este estudo foram utilizados três clusters, pois se percebeu que os agrupamentos identificados com esta composição eram mais adequados para explicar o comportamento dos pesquisados.

Após conhecer o cluster ao qual cada indivíduo pertence, calcularam-se as estatísticas descritivas dentro de cada cluster, para conhecer o nível de qualidade de vida e bem-estar financeiro de cada grupo. Além disso, a fim de verificar se há diferença significativa entre os grupos, aplicou-se a análise de variância. Finalmente, visando aprofundar a caracterização dos clusters, avaliou-se a associação entre os clusters e diversas variáveis relativas ao perfil dos entrevistados (seção 5.1), ao programa contratado (Tabela 2) e às características produtivas das propriedades investigadas.

Como medida de associação utilizou-se o Qui-Quadrado de Pearson. A hipótese nula do teste é de que as variáveis são independentes e a hipótese alternativa é que existe relação entre as variáveis. Se as diferenças entre os valores observados não são estatisticamente diferentes (sig > 0,05), as variáveis são independentes, caso contrário, rejeita-se a hipótese nula de independência. Contudo, o teste do Qui-Quadrado apenas informa so- 
bre a independência entre as variáveis, mas nada diz sobre o grau de associação existente (Pestana \& Gageiro, 2014). Portanto, a fim de medir o grau de associação entre as variáveis, foi calculado o $\mathrm{V}$ de Cramer, o qual varia entre zero e um, isto é, desde ausência da relação até a relação perfeita entre as variáveis (Pestana \& Gageiro, 2014). Utilizouse o Statistical Package for the Social Sciences (SPSS, versão 21.0) forWindows para a análise dos dados.

\section{RESULTADOS E DISCUSSÃO}

Inicialmente, por meio da análise descritiva, a seção 5.1 apresenta as características dos beneficiários e do financiamento Pronaf obtido, a forma de utilização dos recursos e o impacto do financiamento na produção da propriedade. Na seção seguinte são analisados os resultados referentes aos clusters identificados no estudo.

\subsection{Características dos beneficiários e descrição de suas impressões sobre o financiamento, o bem-estar financeiro e a qualidade de vida}

Quanto ao perfil dos participantes (bloco I), a maioria (80,23\%) é do sexo masculino, casado $(74,14 \%)$, não possui dependentes $(50,96 \%)$ e concluiu até o ensino fundamental $(66,54 \%)$. O entrevistado mais novo possui 18 anos e o mais velho, 79 , sendo a média de idade de 51 anos. Quase a totalidade $(99,24 \%)$ tem como ocupação a agricultura, alguns $(25,10 \%)$ também são aposentados e uma pequena parcela também exerce outra profissão seja como autônomo, Consolidação das Leis do Trabalho (CLT) ou servidor público. Na maioria $(59,54 \%)$ das propriedades o núcleo familiar é composto por até três pessoas.

Quanto às características financeiras, 55,90\% dos entrevistados possui cartão de crédito, e a renda mensal familiar apresenta a seguinte configuração: famílias que recebem até $\mathrm{R} \$ 2.000,00$ mensais perfazem $33,20 \%$, de até $\mathrm{R} \$ 2.000,00$ até $\mathrm{R} \$ 4.000,00$ somam $36,38 \%$ e acima desse valor, $29,92 \%$. Boa parte (55,90\%) dos respondentes indicou gastar menos do que ganha e se diz satisfeito com a sua atual situação financeira $(64,10 \%)$. Tais percepções são relevantes para o equilíbrio financeiro do beneficiado, tendo em vista que, segundo Campara eVieira (2016), as famílias devem analisar cuidadosamente as fontes de renda e as prioridades de gastos ou investimentos, evitando, assim, que seja gasto mais do que se tem disponível, tendo em vista a ocorrência de imprevistos.

Também foram avaliadas as condições da propriedade em que vivem os beneficiários entrevistados, a fim de possibilitar uma melhor compreensão das percepções sobre qua- 
lidade de vida. A maioria (37,90\%) das residências dista entre 11 e 20 quilômetros da sede do município, são de alvenaria (70,34\%), possuem energia elétrica (99,24\%), água da rede pública $(72,62 \%)$ e acesso à internet $(77,57 \%)$. Quanto à destinação do lixo doméstico, uma parte é enterrado ou queimado (52,09\%) e outra recolhida pela prefeitura $(47,15 \%)$. Quanto ao transporte, quase a totalidade $(94,68 \%)$ utiliza veículo próprio para locomoção. Em termos de saúde, predominam os atendimentos por postos de saúde $(68,06 \%)$ e/ou os agentes de saúde $(66,54 \%)$, sendo que os entrevistados $(61,83 \%)$ percebem que nos últimos 20 anos a qualidade da saúde pública e gratuita melhorou.

Os resultados referentes ao crédito de Pronaf contratado pelos entrevistados são apresentados na Tabela 2 .

A maioria (55\%) contratou simultaneamente o crédito Pronaf para investimento e custeio no ano de 2019 e já vem utilizando o crédito há mais de quatro anos $(92,40 \%)$. Nos últimos 15 anos, os recursos foram usados predominantemente para o custeio agrícola $(79,80 \%)$, investimentos em máquinas e equipamentos $(47,10 \%)$ e custeio pecuário (34,60\%). Especificamente para o Pronaf Investimentos, predominam a aquisição de tratores e veículos $(46,00 \%)$, implementos agrícolas $(37,10 \%)$ e animais de alto padrão genético (23,20\%). Já na modalidade Pronaf Custeio, os recursos subsidiam principalmente a aquisição de insumos para correção do solo $(69,60 \%)$ e de sementes transgênicas $(54,80 \%)$ ou de sementes com elevado padrão de germinação $(54,00 \%)$.

Quanto às características produtivas e de comercialização das propriedades, pode-se constatar que nas propriedades predominam a produção de grãos $(38,00 \%)$ e a produção mista (36,10\%). Esta produção é em sua maioria comercializada a partir das cooperativas ou associações das quais os beneficiários fazem parte $(66,90 \%)$, sendo que $72,20 \%$ deles participam de alguma dessas associações. Quase a totalidade dos entrevistados afirma que consegue atender as orientações do projeto pelo menos em sua maioria $(97,00 \%)$ e que seu contrato não possui dívidas atrasadas $(99,20 \%)$.

Além disso, entendem que o crédito impulsionou a produção na propriedade (97,00\%), com predomínio de aumentos produtivos entre 30\% e 50\% (56,20\%). Dentre as principais tecnologias implementadas para o aumento da produtividade destacamse a compra de tratores, plantadeiras e colheitadeiras $(39,92 \%)$, o uso de energia elétrica $(30,42 \%)$ e o melhoramento genético de animais $(23,19 \%)$.

As análises da sequência referem-se aos blocos III e IV e avaliam a percepção dos beneficiários quanto à qualidade de vida e ao bem-estar financeiro, respectivamente. A Tabela 3 apresenta as estatísticas descritivas dos domínios da qualidade de vida. 


\section{TABELA 2}

\section{Características do Pronaf contratado pelos entrevistados}

\begin{tabular}{|c|c|c|}
\hline Variável & Categorias & Percentua \\
\hline \multirow[t]{5}{*}{ Tipo de Pronaf } & Custeio & 26,60 \\
\hline & Investimentos & 18,60 \\
\hline & Custeio e Investimentos (simultâneo) & 55,00 \\
\hline & Agroindústria & 1,10 \\
\hline & Eco & 0,40 \\
\hline Ano de contratação do & Em 2019 & 76,43 \\
\hline \multirow[t]{3}{*}{ último crédito Pronaf } & Em 2018 & 9,51 \\
\hline & Em 2017 & 2,66 \\
\hline & Anterior a 2017 & 11,41 \\
\hline Tempo de utilização & Um ano & 1,90 \\
\hline \multirow[t]{3}{*}{ do crédito rural Pronaf } & Dois anos & 2,28 \\
\hline & Três anos & 3,42 \\
\hline & Quatro ou mais anos & 92,40 \\
\hline Utilização do Pronaf & Custeio agrícola & 79,80 \\
\hline \multirow[t]{5}{*}{ nos últimos 15 anos* } & Custeio pecuário & 34,60 \\
\hline & Pronaf para aquisição de animais & 21,30 \\
\hline & $\begin{array}{l}\text { Investimento para aquisição de equipamentos, implementos, } \\
\text { tratores ou similares }\end{array}$ & 47,10 \\
\hline & Investimento para aquisição de veículo & 2,30 \\
\hline & Pronaf utilizado de outras formas (não especificadas) & 5,70 \\
\hline \multirow[t]{6}{*}{ Pronaf Investimentos* } & Implementos agrícolas (pulverizadores, motores estacionários, etc.) & 37,10 \\
\hline & Tratores, caminhões, motos, veículos utilitários ou similares & 46,00 \\
\hline & Tanques de expansão, resfriadores, ordenhadeiras, etc & 21,70 \\
\hline & Animais de alto padrão genético (reprodutores ou matrizes) & 23,20 \\
\hline & Construção de silos, galpões, celeiros, abrigos, cercas e estrebarias & 22,40 \\
\hline & Outras melhorias (não especificadas) & 22,10 \\
\hline \multirow[t]{6}{*}{ Pronaf Custeio* } & $\begin{array}{l}\text { Aquisição de sementes, mudas ou similares com elevado padrão } \\
\text { de germinação }\end{array}$ & 54,00 \\
\hline & Aquisição de sementes transgênicas & 54,80 \\
\hline & $\begin{array}{l}\text { Aquisição de insumos (calcário, defensivos, etc.) para correção } \\
\text { de solo e aumento de produtividade }\end{array}$ & 69,60 \\
\hline & $\begin{array}{l}\text { Aquisição de insumos (vacinas, vermífugos, minerais, etc.) que permitam } \\
\text { a qualidade da saúde dos animais, preservando sua produtividade }\end{array}$ & 6,50 \\
\hline & Outras melhorias & 12,90 \\
\hline & Não propiciou melhorias ou nunca contratei & 2,70 \\
\hline
\end{tabular}

* Percentual ultrapassa $100 \%$, pois os entrevistados podem marcar mais de uma alternativa. 


\section{TABELA 3}

Estatística descritiva dos domínios da escala de qualidade de vida

\begin{tabular}{lcrccr}
\hline Domínio & Média & Mediana & Desvio padrão & Mínimo & Máximo \\
\hline Físico & 70,44 & 71,43 & 12,57 & 35,71 & 100,00 \\
Psicológico & 69,71 & 70,83 & 10,07 & 33,33 & 95,83 \\
Relações sociais & 73,92 & 75,00 & 11,00 & 25,00 & 100,00 \\
Ambiental & 63,52 & 65,63 & 10,14 & 25,00 & 90,63 \\
\hline
\end{tabular}

Fonte: dados da pesquisa (2020).

Em relação à qualidade de vida, quando questionados sobre o nível de satisfação geral, $71,50 \%$ dos respondentes a classificaram como boa. Estando os domínios numa escala de 0 a 100, identifica-se que os beneficiários possuem, em média, uma percepção positiva da qualidade de vida, assim como foi observado em Aleixo et al. (2007) e Gouveia (2010). Os domínios físicos e relações sociais apresentam as maiores médias, enquanto o ambiental é o de pior desempenho, resultado semelhante ao encontrado por Gouveia (2010), que investigou os beneficiários do Pronaf Jovem (pronafianos). Portanto, percebese uma tendência da percepção positiva dos beneficiários do programa, indicando que este tem conseguido atingir um dos seus objetivos, de constantemente melhorar a qualidade de vida dos agricultores familiares.

No domínio relações sociais, na escala de 1 a 5 , os beneficiários indicaram estarem satisfeitos com suas relações pessoais (média $=4,01$ ), com o apoio que recebem de amigos (média $=3,91$ ) e com suas vidas sexuais (média $=3,96)$. Na escala de 0 a 100 , observou-se uma frequência expressiva de entrevistados na faixa entre $70 \%$ e $80 \%$, indicando que, em termos de qualidade de vida, os beneficiários estão satisfeitos. Este resultado é bastante representativo quanto aos sentimentos positivos. Gouveia (2010), ao comparar pronafianos com jovens não beneficiários do programa, também identificou uma diferença significativa de maior percepção de qualidade de vida no domínio social por parte daqueles que receberam o benefício. Silva e Bernardes (2014: 740) reforçam que, para atingir o seu "propósito» de melhorar a qualidade de vida dos agricultores familiares, as ações do Pronaf «consideram, implicitamente, a relevância da formação de capital humano e social no meio rural, o que tende a corroborar o achado desta investigação».

Nos demais domínios as maiores frequências concentram-se nas faixas em torno de $50 \%$ a $80 \%$, indicando menores níveis de satisfação quanto aos aspectos físicos, psicológicos e ambientais.

Os questionamentos do domínio físico visam avaliar os aspectos relativos a dor e desconforto, energia e fadiga, sono e repouso, mobilidade, atividades da vida cotidiana, de- 
pendência de medicação ou de tratamentos e capacidade de trabalho. As avaliações das variáveis relativas a este domínio indicam que a maioria dos participantes apresenta uma boa capacidade de locomoção e muita energia para desempenhar as atividades do dia a dia, além de estarem satisfeitos com o seu sono e sua capacidade de desempenhar as atividades e trabalhar.

Já as variáveis do domínio psicológico avaliam a percepção referente aos sentimentos positivos; pensar, aprender, memória e concentração; autoestima, imagem corporal e aparência; sentimentos negativos; espiritualidade, religião, crenças pessoais. As variáveis relativas a este domínio indicam que os entrevistados possuem uma baixa frequência de sentimentos negativos e estão satisfeitos consigo mesmo. No entanto, quando questionados sobre o quanto aproveitam a vida, $48,70 \%$ responderam «mais ou menos» e $8 \%$ responderam que aproveitam muito pouco.

Os questionamentos do domínio meio ambiente analisam fatores relacionados à segurança física e proteção; ambiente; recursos financeiros; cuidados de saúde e sociais: disponibilidade e qualidade; acesso às novas informações e habilidades; participação e oportunidades de recreação ou lazer; ambiente físico: poluição, ruído, trânsito, clima; transporte. Os entrevistados estão satisfeitos com as condições do local onde moram e com o seu meio de transporte. Destacam-se também as avaliações positivas nos aspectos relativos à segurança, à qualidade do ambiente físico, e ao acesso aos serviços de saúde. Como os municípios pesquisados são pequenos, na maioria dos casos, há maior facilidade de propiciar bons resultados nestes fatores.

Ainda no domínio meio ambiente, destaca-se que a questão de pior resultado foi «Em que medida você tem oportunidades de atividade de lazer?", sendo que $22,40 \%$ responderam «muito pouco» e $46 \%$ «mais ou menos». Os agricultores informam que até há algumas oportunidades de lazer, mas a participação é pequena devido à rotina do trabalho ou ao manejo dos animais na propriedade, o que dificulta a saída por maiores períodos de tempo.

Historicamente coube ao rural a função da produção agropecuária, alimentação e fornecimento da matéria-prima para a indústria, pois os projetos para agricultura tinham enfoque produtivo e econômico, com a inclusão recente das áreas de preservação ambientais. O lazer e a prática de atividades recreativas foram considerados ações secundárias no meio rural, sendo classificado apenas como um lugar para trabalhar e produzir, sem analisar a perspectiva humana e social, ou seja, a qualidade de vida dos agricultores (Maziero et al., 2019). 
Observa-se a importância da compreensão da influência dos ambientes de convívio e lazer no meio rural, bem como na qualidade de vida dos seus moradores, estando vinculado ao conceito de acesso à saúde, à educação, à comunicação, ao esporte, ao lazer e outros, no seu local de moradia e comunidade. O lazer é algo necessário e formador do bem-estar e da saúde das populações, tanto urbanas quanto rurais, devendo ser percebido como prática da manutenção do convívio social, da saúde e do exercício da cidadania. O rural precisa ser visto como um local de moradia e relações sociais, sendo fundamental a criação de políticas públicas e projetos que visem atender a qualidade de vida pelo viés do lazer, evitando que a ausência de estruturas de lazer favoreça um novo esvaziamento das áreas rurais (Maziero et al., 2019).

Em seguida, buscou-se analisar o nível de bem-estar financeiro. Numa escala de zero a cem, a resposta média foi de 54,69 pontos, indicando uma percepção apenas intermediária em relação ao seu nível de bem-estar financeiro. A maioria das respostas se encontra no intervalo entre $50 \%$ e $70 \%$. Destaca-se ainda o fato de que o valor máximo foi 82,5 pontos, indicando que nenhum beneficiário se considera em um alto nível de bem-estar financeiro. As questões com piores avaliações, em uma escala de 1 a 5, indicam que os beneficiários frequentemente tendem a se preocupar com o pagamento das despesas do dia a dia ( $\mathrm{e}$ às vezes percebem que as finanças controlam as suas vidas).

De acordo com o CFPB (2015), o bem-estar financeiro das pessoas ocorre a partir do ato de controlar suas finanças, ser capaz de pagar as contas em dia, ter reservas financeiras e poder "aproveitar a vida", com um planejamento financeiro que permita tirar férias, viajar, trabalhar menos e usufruir mais do tempo em família. Nesse sentido, o planejamento aliado ao controle financeiro contribui para que haja sobra de recursos no final do mês, permitindo mais tranquilidade no caso do surgimento de despesas inesperadas, ou imprevistos, e maiores possibilidades de uso dos recursos para atividades de lazer, viagens, etc.

Portanto, como política, o Pronaf precisa ir além da concessão do recurso, devendo conscientizar os beneficiários da importância da gestão financeira adequada, pois uma boa gestão dos recursos é capaz de proporcionar o bem-estar financeiro e a melhoria da qualidade de vida (Kim, Garman \& Sorhaindo, 2003).

\subsection{Análise de clusters: identificando perfis entre os entrevistados}

Após a construção das escalas de qualidade de vida e bem-estar financeiro, estas foram utilizadas como variáveis de entrada para a análise de cluster. A Tabela 4 apresenta os re- 
sultados bem como uma análise de variância (anova) para identificação de possíveis diferenças entre os clusters.

\section{TABELA 4}

Média, desvio padrão e anova dos clusters formados pelo método de Ward

\begin{tabular}{lccccccr}
\hline Escala/domínio & \multicolumn{2}{c}{ Cluster $\mathbf{1}(\mathbf{n}=\mathbf{2 9})$} & \multicolumn{2}{c}{ Cluster $\mathbf{2}(\mathbf{n}=\mathbf{1 2 3})$} & \multicolumn{3}{c}{ Cluster $\mathbf{3}(\mathbf{n}=\mathbf{1 1 1})$} \\
\hline & Média & Desvio padrão & Média & Desvio padrão & Média & Desvio padrão & Anova \\
\hline Físico & 54,19 & 8,59 & 65,43 & 9,65 & 80,25 & 7,70 & $139,63^{*}$ \\
Psicológico & 54,80 & 8,04 & 67,68 & 8,23 & 75,86 & 6,98 & $93,86^{*}$ \\
Relações sociais & 55,03 & 10,17 & 74,25 & 8,11 & 78,49 & 8,59 & $64,64^{*}$ \\
Ambiental & 50,22 & 8,14 & 60,77 & 8,15 & 70,04 & 7,50 & $86,83^{*}$ \\
Bem-estar financeiro & 53,02 & 8,72 & 53,25 & 12,88 & 56,71 & 10,83 & 2,91 \\
\hline
\end{tabular}

* Significativo a $1 \%$; teste $\mathrm{F}$ robusto de Welch devido à ausência de homogeneidade das variâncias.

Fonte: dados da pesquisa (2020).

A análise resultou em três clusters distintos. O cluster 1 é composto por um grupo de 29 beneficiários os quais apresentam as piores percepções para os quatro domínios da qualidade de vida e para o bem-estar financeiro. No cluster 2, o maior grupo (123 beneficiários), predominam as percepções intermediárias. Ao passo que, no cluster 3, tem-se os indivíduos com as melhores percepções médias. A anova e o testes post hoc ${ }^{1}$ indicam que, para as quatro dimensões da qualidade de vida, as diferenças entre os três grupos são significativas. Já para a escala de bem-estar financeiro, a anova não foi significativa, indicando que os grupos apresentam percepções semelhantes sobre este fator.

O cluster 1 caracteriza-se por certa indiferença em relação à qualidade de vida (média dos domínios de 53,45 pontos), já o cluster 3 percebe-se como uma boa qualidade de vida (média de 72,27 pontos). Do mesmo modo que na análise geral, em todos os grupos, o domínio com as piores percepções é o ambiental. Em todos os grupos o bem-estar financeiro apresenta os valores médios mais baixos, em torno de $50 \%$, indicando que nos três grupos a percepção de bem-estar financeiro é pior do que a percepção em relação a qualquer um dos domínios da qualidade de vida.

Finalmente, buscou-se avaliar se os diferentes grupos são distintos quanto as demais variáveis avaliadas no estudo (blocos I e II do questionário). A Tabela 5 apresenta os re-

1. Teste Post-hoc de Tukey para os domínios físico, psicológico e ambiental e o teste de GamesHowell para o domínio relações sociais indicaram que todas as diferenças de média entre os clusters são significativas a $1 \%$. 
sultados significativos ao nível de $1 \%$ do teste Qui-Quadrado e doV de Cramer, os quais avaliam associação entre os clusters e as demais variáveis analisadas.

TABELA 5

Qui-quadrado e V de Cramer para a associação entre os clusters e as demais variáveis significativas

\begin{tabular}{|c|c|c|c|c|c|c|}
\hline Variável & Categorias & $\begin{array}{c}\text { Cluster } \\
1\end{array}$ & $\begin{array}{c}\text { Cluster } \\
2 \\
\end{array}$ & $\begin{array}{c}\text { Cluster } \\
3 \\
\end{array}$ & $\begin{array}{c}\text { Qui- } \\
\text { Quadrado }\end{array}$ & $\begin{array}{c}\text { V de } \\
\text { Cramer }\end{array}$ \\
\hline \multirow[t]{4}{*}{ Distância da propriedade } & Até $5 \mathrm{~km}$ & $20,7 \%$ & $21,5 \%$ & $41,4 \%$ & $20,779^{*}$ & $0,200^{*}$ \\
\hline & Entre $6 \mathrm{~km} \mathrm{e} 10 \mathrm{~km}$ & $17,2 \%$ & $37,2 \%$ & $27,0 \%$ & & \\
\hline & Entre $11 \mathrm{~km} \mathrm{e} 20 \mathrm{~km}$ & $37,9 \%$ & $31,4 \%$ & $24,3 \%$ & & \\
\hline & Acima de $20 \mathrm{~km}$ & $24,1 \%$ & $9,9 \%$ & $7,2 \%$ & & \\
\hline \multirow[t]{3}{*}{ Renda bruta mensal familiar } & Até $\mathrm{R} \$ 2.000,00$ & $58,6 \%$ & $35,7 \%$ & $23,3 \%$ & $13,629^{*}$ & $0,167^{*}$ \\
\hline & De $\mathrm{R} \$ 2.000,01$ a $\mathrm{R} \$ 4.000,00$ & $24,1 \%$ & $33,9 \%$ & $43,7 \%$ & & \\
\hline & Acima de $\mathrm{R} \$ 4.000,00$ & $17,2 \%$ & $30,4 \%$ & $33,0 \%$ & & \\
\hline \multirow[t]{2}{*}{ Nível educacional } & Até ensino fundamental & $82,8 \%$ & $71,5 \%$ & $56,8 \%$ & $9,582^{*}$ & $0,191^{*}$ \\
\hline & Ensino médio ou superior & $17,2 \%$ & $28,5 \%$ & $43,2 \%$ & & \\
\hline \multirow[t]{2}{*}{ Possui cartão de crédito } & Não & $69,0 \%$ & $46,3 \%$ & $38,7 \%$ & $8,520^{\star}$ & $0,180^{*}$ \\
\hline & $\operatorname{Sim}$ & $31,0 \%$ & $53,7 \%$ & $61,3 \%$ & & \\
\hline \multirow[t]{2}{*}{ Gastos } & Gasta menos do que ganha & $31,0 \%$ & $50,4 \%$ & $68,5 \%$ & $15,890^{*}$ & $0,246^{*}$ \\
\hline & Gasta igual ou mais do que ganha & $69,0 \%$ & $49,6 \%$ & $31,5 \%$ & & \\
\hline Faz parte de associação & $\operatorname{Sim}$ & $51,7 \%$ & $70,7 \%$ & $79,3 \%$ & $8,970^{*}$ & $0,185^{\star}$ \\
\hline ou cooperativa & Não & $48,3 \%$ & $29,3 \%$ & $20,7 \%$ & & \\
\hline \multirow[t]{3}{*}{ Grau de satisfação financeira } & Insatisfeito(a) & $13,8 \%$ & $13,9 \%$ & $8,1 \%$ & $15,205^{*}$ & $0,170^{*}$ \\
\hline & Indiferente & $41,4 \%$ & $28,7 \%$ & $15,3 \%$ & & \\
\hline & Satisfeito(a) & $44,8 \%$ & $57,4 \%$ & $76,6 \%$ & & \\
\hline
\end{tabular}

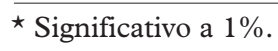

Fonte: dados da pesquisa (2020).

Os resultados indicam que todas as associações são significativas e baixas. O cluster 1, com as piores percepções de qualidade de vida, é também o cluster com maior percentual de propriedades mais distantes (acima de $20 \mathrm{~km}$ ), com mais beneficiários que não possuem cartão de crédito e que gastam igual ou mais do que ganham. Além disso é o cluster com mais baixo nível educacional e com menores rendas. Também apresenta o menor percentual de entrevistados associados a cooperativas e satisfeitos com sua situação financeira. A relação entre menor percepção de bem-estar financeiro e menor qualificação educacional também foi identificada por Diniz et al. (2014).

Complementarmente, Gordia, Quadros e Campos (2009) destacam que o domínio ambiental da qualidade de vida, que se refere às facetas de segurança física e proteção, 
ambiente físico (poluição, ruído, trânsito, clima e transporte) e do lar dos respondentes, recursos financeiros, disponibilidade e qualidade dos cuidados de saúde e sociais, oportunidades de recreação/lazer, etc., pode ser um ponto vulnerável às classes socioeconômicas menos favorecidas.

Por outro lado, o cluster 3, de melhor qualidade de vida, também é o cluster em que predominam propriedades mais próximas da sede dos municípios, mais associadas às cooperativas e associações. $\mathrm{O}$ fato de pertencer a uma cooperativa se mostra relevante neste cluster, indicando que estas associações possam, atualmente, estar oferecendo assessoria no planejamento e acompanhamento ao projeto a ser executado, uma evolução do cenário identificado por Sena et al. (2011), indicando a importância das associações e cooperativas no processo de planejamento do orçamento. Tal resultado vai ao encontro do que foi apontado por Zani e Costa (2014), de que estudos estão indicando avanços do Pronaf no que se refere ao associativismo local. Complementarmente, Silva e Bernardes (2014: 740) ressaltam que uma das ações do Pronaf é o incentivo «a associações, conselhos e cooperativas rurais, e serviços de Assistência Técnica e Extensão Rural (Ater) para os produtores familiares».

Cabe ressaltar também que os integrantes deste cluster possuem maiores níveis de renda, de educação, mais acesso ao cartão de crédito, conseguem gastar menos do que ganham e também a maioria está satisfeita com a sua situação financeira. Tais relações são explicadas pela CFPB (2015), que indica que ter controle sobre as finanças e ser capaz de pagar as contas em dia traz segurança financeira e aumenta significativamente o bemestar financeiro pessoal.

\section{CONSIDERAÇÕES FINAIS}

O Pronaf concede financiamentos com o objetivo de fortalecer as atividades desenvolvidas pela agricultura familiar, promovendo a geração de renda e a melhora da qualidade de vida dos agricultores. Como uma política pública, o programa deve ser alvo de avaliações, e uma das formas de verificar seus resultados é mensurar a percepção dos seus beneficiários finais, ou seja, das famílias agricultoras contratantes das diversas modalidades do crédito. Assim, este estudo se propôs a analisar a percepção do financiamento, do bemestar financeiro e da qualidade de vida dos beneficiários do Pronaf.

Os resultados indicam que a contratação do crédito, em sua maioria, tanto para custeio quanto para investimentos, tem proporcionado aos produtores a aquisição dos insumos, equipamentos e máquinas e tem sido capaz de promover melhorias diretas na pro- 
priedade, inclusive no aumento da produção, o que, consequentemente, amplia a geração de renda. As propriedades beneficiadas, em sua maioria, possuem uma estrutura mínima adequada, com energia, água encanada e casas de alvenaria. Observa-se, ainda, alguma dificuldade com acesso ao transporte público e recolhimento de lixo doméstico. $\mathrm{O}$ acesso à saúde tem melhorado nos últimos anos e acontece, principalmente, através de agentes e postos de saúde.

Entretanto foi constatado que a maioria dos recursos do Pronaf está sendo investida na produção das comodities mais produzidas na região. Tais resultados vão ao encontro da literatura que apresenta como um dos grandes desafios para o Pronaf o fomento à diversidade de atividades agrícolas dos agricultores familiares (Aquino \& Schneider, 2015; Troian \& Machado, 2020).

O estudo da qualidade de vida indicou, por meio da escala WHOQOL-Bref, que, de maneira geral, os beneficiários a percebem como boa. Quanto aos domínios específicos, identificou-se que os domínios físico e relações sociais apresentam as maiores médias, enquanto que o ambiental é o de pior desempenho, achados esses que corroboram os resultados de investigações anteriores e reforçam que o programa tem conseguido atingir o objetivo de melhorar a qualidade de vida dos beneficiários. Por outro lado, os beneficiários percebem-se com um nível intermediário de bem-estar financeiro.

Observou-se ainda que, quando os indivíduos são analisados em grupos, aquele com as piores percepções de qualidade de vida é também aquele com pior percepção de bemestar financeiro (cluster 1). Isso se reflete em indivíduos que possuem propriedades mais distantes da sede do município, mais beneficiários que não possuem cartão de crédito e que gastam igual ou mais do que ganham. Além disso, é o cluster com mais baixo nível educacional e com menores rendas. Ao passo que no grupo com melhor qualidade de vida (cluster 3), observa-se maior percentual de integrantes com maiores níveis de renda, de educação, mais acesso ao cartão de crédito e maior satisfação com a situação financeira.

Portanto, os resultados sugerem que o Pronaf na região estudada tem sido capaz de melhorar as condições produtivas das famílias e de qualidade de vida, excetuando-se alguns aspectos do domínio ambiental que ainda precisam ser melhorados. Por outro lado, o nível de bem-estar financeiro destas famílias é intermediário e medidas estratégicas deveriam ser pensadas. Neste sentido, faz-se importante a atuação das associações e cooperativas de agricultores, que despontam como elementos norteadores, principalmente no processo de planejamento do orçamento. 
Os resultados médios sugerem que os beneficiários frequentemente tendem a se preocupar com o pagamento das despesas do dia a dia e às vezes percebem que as finanças controlam as suas vidas. Possivelmente, o crédito Pronaf está entre as despesas relevantes para este contexto, indicando que medidas governamentais como uma melhor análise do limite de crédito, a ampliação dos prazos de financiamento e a diminuição dos juros são formas efetivas de redução do impacto da dívida na vida financeira dos beneficiários. Ainda, dado que grande parte dos beneficiários possui até o ensino fundamental, a oferta de cursos de alfabetização financeira e de gestão financeira podem permitir um maior entendimento dos contratos e melhores comportamentos financeiros. Tais cursos poderiam ser oferecidos pelo próprio sistema bancário que concede os créditos ou pelas cooperativas e associações das quais a maioria dos beneficiários fazem parte.

Este estudo inova por ser o primeiro a avaliar o bem-estar financeiro dos pronafianos e também por avaliar a qualidade de vida em uma região ainda não pesquisada. Entretanto, não é capaz de esgotar essas temáticas. Estudos que permitam ampliar a avaliação da política pública nesses temas são promissores. No campo financeiro, a forma como os recursos oriundos do programa compõe a renda das famílias, como elas priorizam os gastos, quais os principais itens consumidos e os impactos na renda mensal, como é realizado o controle dos custos e o pagamento da dívida e os resultados monetários com a atividade produtiva financiada pelo programa são questões ainda por investigar. Já em termos de qualidade de vida, um estudo longitudinal das famílias que contratam o Pronaf sucessivamente poderia revelar o impacto de longo prazo do programa na melhoria da vida dos beneficiários.

Também são promissores os estudos qualitativos sobre o tema, já que a maioria da literatura sobre o Pronaf tem o enfoque quantitativo. Abordagens qualitativas podem propiciar um entendimento em maior profundidade dos reais efeitos da política na estrutura produtiva e na qualidade de vida e bem-estar dos agricultores.

Este estudo coletou dados em todos os vinte e cinco municípios do Corede Missões, tornando a amostra representativa desta região. Entretanto, uma limitação é a impossibilidade de generalização dos resultados para as demais regiões brasileiras, abrindo, assim, espaço para que a pesquisa possa ser replicada em outras localidades. Outra limitação é a possibilidade de existência do viés de resposta, o qual procurou-se reduzir a partir da padronização dos procedimentos de aplicação do instrumento. 


\section{AGRADECIMENTOS}

As autoras agradecem aos revisadores da revista Historia Agraria pela revisão qualificada, comentários, sugestões e correções deste artigo.

\section{REFERÊNCIAS}

Aleixo, C. E. M, Oliveira, L. A. S., Reis, A. P. L. Dos, Muniz, K. T. \& Lima, P. V. P. S. (2007). Impactos do Pronaf nos indicadores de qualidade de vida de seus beneficiados no assentamento Santana-CE. In Anais doVII Congresso da Sociedade Brasileira de Sistemas de Produção (CSBPS) (pp. 1-11). Fortaleza: Sociedade Brasileira de Sistemas de Produção.

Aquino, J. R. DE \& SCHNEIDER, S. (2015). O Pronaf e o desenvolvimento rural brasileiro: Avanços, contradições e desafios para o futuro. In C. GRISA \& S. SCHNEIDER (Orgs.), Políticas públicas de desenvolvimento rural no Brasil. Porto Alegre: UFRGS.

Banco Central do Brasil (BCB) (2017). FAQ-Programa Nacional de Fortalecimento da Agricultura Familiar (Pronaf). https://www.bcb.gov.br/estabilidadefinan ceira/reportmicrrural?path $=$ conteudo $\% 2 \mathrm{FMDCR} \% 2 \mathrm{FReports} \% 2 \mathrm{FqvcMunicipio} . \mathrm{rdl}$ \&nome $=$ Quantidade $\% 20 \mathrm{e} \% 20$ Valor $\% 20$ dos $\% 20$ Contratos $\% 20$ por $\% 20$ Munic $\%$ C3 $\% A D$ pio\&exibeparametros $=$ true\&botoesExportar=true

Banco Nacional do Desenvolvimento (BNDES) (2020). Pronaf-Programa Nacional de Fortalecimento da Agricultura Familiar. https://www.bndes.gov.br/wps/portal/site/ home/financiamento/produto/pronaf

Decreto no 1.946. Cria o Programa Nacional de Fortalecimento da Agricultura Familiar-PRONAF, e dá outras providências. Diário Oficial da União, seção 1, 01/07/1996, p. 11854. Brasília, 28 de junho de 1996. http://www.planalto.gov.br/ccivil_03/decreto/D1946.htm

Bianchini, V. (2015). Vinte anos do Pronaf, 1995-2015: Avanços e desafios. Brasília: Ministério do Desenvolvimento Agrário.

BINDER, M. \& COAD, A. (2015). Heterogeneity in the Relationship between Unemployment and Subjective Wellbeing: A Quantile Approach. Economica, 82 (328), 865-891.

CAmpara, J. P. \& Vieira, K. M. (2016). Beneficiários do Programa Bolsa Família: relações com as finanças e impacto na satisfação global de vida. Nova Economia, 26 (3), 981-1006.

CAstro, F. J. A. DE \& CAmpos, R. T. (2010). Os impactos do Programa Nacional de Fortalecimento da Agricultura Familiar na qualidade de vida dos beneficiários no estado do Ceará: Um estudo de caso. Revista de Desenvolvimento do Ceará, (01), 92-111. 
Chan, S. F., ChaU, A. W. L. \& Chan, K.Y. K. (2012). Financial Knowledge and Aptitudes: Impacts on College Students' Financial Well-Being. College Student fournal, 46 (1), 114-133.

Chen, I. J., Gu,Y. \& Chen. C. (2012). Family Resource Management Style and Life Adjustment of Low-Income Single Mothers in China. Social Behavior and Personality: An international journal, 40 (6), 959-970.

Consumer Financial Protection Bureau (CFPB) (2015). Financial Well-Being: The Goal of Financial Education. Washington, DC: Consumer Financial Protection Bureau. http://files.consumerfinance.gov/f/201501_cfpb_report_financial-well-being.pdf

Delafrooz, N. \& Paim, L. (2011). Determinants of Financial Wellness among Malaysia Workers. African fournal of Business Management, 5 (24), 10092-10100.

Diniz, A. P. C., Vieira, K. M., Potrich, A. C. G. \& CAMPara, J. P. (2014). Influência das variáveis socioeconômicas e demográficas no bem-estar financeiro: Um estudo do comportamento maranhense. Revista Uniabeu, 7 (17), 218-234.

FLECK, M. P. et al. (2000). Aplicação da versão em português do instrumento abreviado de avaliação da qualidade de vida "WHOQOL-bref". Revista de Saúde Pública, 34 (2), 178-183.

Gordia, A. P., QuAdros, T. M. B. DE \& CAMPOS, W. DE (2009).Variáveis sociodemográficas como determinantes do domínio meio ambiente da qualidade de vida de adolescentes. Ciência \& Saúde Coletiva, 14 (6), 2261-2268.

Gouveia, C. N. N. A. (2010). Avaliação do impacto do Programa Nacional de Fortalecimento da Agricultura Familiar (Pronaf) na qualidade de vida de jovens agricultores paraibanos. Dissertação de Mestrado. Paraíba: Universidade Federal da Paraíba.

Grisa, C., Wesz Junior, V. J. \& BuchweItz, V. D. (2014). Revisitando o Pronaf: Velhos questionamentos, novas interpretações. Revista de Economia e Sociologia Rural, 52 (2), 323-346.

Hair, J. F., Black, W. C., Babin, B. J. \& Anderson R. E. (2010). Multivariate Data Analyses. $7^{\text {a }}$ ed. Upper Saddle River: Pearson Prentice Hall.

Harper, A. \& Power, M. (2013). Steps for Checking and Cleaning Data and Computing Domain Scores for the WHOQOL-Bref. http://www.ufrgs.br/psiquiatria/psiq/whoqol86.html

Hespanhol, A. N. (1997). Políticas públicas, modernização e crise da agricultura brasileira. Revista Faz Ciência, 1 (1), 38-49.

Joo, S. (2008). Personal Financial Wellness. In J. J. XIAO (Ed.), Handbook of Consumer Finance Research (pp. 21-34). New York: Springer.

Kim, J., Garman, E. T. \& Sorhaindo, B. (2003). Relationships among Credit Counseling Clients' Financial Wellbeing, Financial Behaviors, Financial Stressor Events, and Health. fournal of Financial Counseling and Planning, 14 (2), 75-87. 
Kunkel, F. I. R., Vieira, K. M. \& Potrich, A. C. G. (2015). Causas e consequências da dívida no cartão de crédito: Uma análise multifatores. Revista de Administração (São Paulo), 50 (2), 169-182.

Lobato, L. DEV. C. (2016). Políticas sociais e modelos de bem-estar social: Fragilidades do caso brasileiro. Revista Saúde Debate, 40 (spe), 87-97.

Malhotra, N. K. (2011). Pesquisa de marketing: Uma orientação aplicada. $4^{\text {a }}$ ed. Porto Alegre: Bookman.

Malone, K., Stewart, S. D., Wilson, J. \& Korsching P. F. (2010). Perceptions of Financial Well-Being among American Women in Diverse Families. Fournal of Family and Economic Issues, 31 (1), 63-81.

Maziero, C., Godoy, C. M. T., Campos, J. R. DA R. \& Mello, N. A. DE (2019). O lazer como fator de permanência e reprodução social no meio rural: Estudo do município de Saudade do Iguaçu, PR. Interações (Campo Grande), 20 (2), 509-522.

Mello, M. M. S. De, Silveira, S. F. R. \& Silva, F. C. (2017). Avaliação dos efeitos do Programa Nacional de Fortalecimento da Agricultura Familiar (Pronaf) na Vida das Mulheres beneficiárias: Qualitative Comparative Analysis (QCA) de Casos em Municípios de Minas Gerais. In Anais do XLI Encontro da ANPAD. São Paulo: ANPAD.

Ministério do Desenvolvimento Agrário (2014). Manual do agente emissor de declaração de aptidão ao Pronaf. http://dap.mda.gov.br/dapweb/ManualDAP/MANUAL \%20DO\%20AGENTE\%20EMISSOR.pdf

MinistéRIo do DeSEnVOlvimento AgRÁRIo (2018). Sobre o Programa. http://www.mda. gov.br/sitemda/secretaria/saf-creditorural/sobre-o-programa

MirandA, D. L. R. \& Gomes, B. M. A. (2016). Programa Nacional de Fortalecimento da Agricultura Familiar:Trajetórias e desafios no Vale do Ribeira, Brasil. Sociedade E Natureza, 28 (3), 397-408.

Neves, D. P. (2007). Agricultura Familiar: Quantos ancadouros! In B. M. Fernandes, M. I. M. MARQues \& J. C. SuZUKi (Orgs.), Geografia Agrária:Teoria e poder (pp. 211270). São Paulo: Expressão Popular.

Norvilitis, J. M., Szablicki, P. B. \& WiLson, S. D. (2003). Factors Influencing Levels of Credit Card Debt in College Students. Fournal of Applied Social Psychology, 33 (5), 935-947.

Organisation for ECONOMic Co-Operation AND Development (OECD) (2018). OECD/INFE Toolkit for Measuring Financial Literacy and Financial Inclusion. OECD Publishing. http://www.oecd.org/daf/fin/financial-education/2018-INFEFinLit-Measurement-Toolkit.pdf

Pestana, M. H. \& Gageiro, J. N. (2014). Análise de dados para ciências sociais: A complementaridade do SPSS. $6^{\text {a }}$ ed. Lisboa: Sílabo. 
PIREs, M. J. S. (2013). Contradições em processo: Um estudo da estrutura e evolução do Programa Nacional de Fortalecimento da Agricultura Familiar (PRONAF): 2000 a 2010. Brasília: Ipea.

PlaGnol, A. C. (2011). Financial Satisfaction over the Life Course:The Influence of Assets and Liabilities. Fournal of Economic Psychology, 32 (1), 45-64.

Santos, C. F. dos, Siqueira, E. S., Oliveira, I. J. C. DE, Dantas, M. E. C. \& Maia, Z. M. G. (2012). Agricultura familiar e convívio sustentável numa perspectiva interdisciplinar. Revista de Políticas Públicas, 16 (1), 25-35.

Santos, D. B., Silva, W. M. DA, Flores, E. \& Norvilitis, J. M. (2016). Predictors of Credit Card Use and Perceived Financial Well Being in Female College Students: A Brazil United States Comparative Study. International fournal of Consumer Studies, 40 (2), 133-142.

Saron, F. De A. \& Hespanhol, A. N. (2012). O Pronaf e as Políticas de Desenvolvimento Rural no Brasil: $\mathrm{O}$ desafio da (re)construção das políticas de apoio à agricultura familiar. Geo UERF, 2 (23), 656-683.

SCHNEIDER, S. (2003). Teoria social, agricultura familiar e pluriatividade. Revista Brasileira de Ciências Sociais, 18 (51), 99-122.

SChNeider, S., CAZELla, A. A. \& MATTEI, L. (2004). Histórico, caracterização e dinâmica recente do Pronaf-Programa Nacional de Fortalecimento da Agricultura Familiar. In A. A. Cazella, S. Schneider, M. K. Silva \& P. E. Moruzzi-Marques (Orgs.), Políticas públicas e participação social no Brasil rural (pp. 21-51). Porto Alegre: UFRGS.

Sena, J. De O., Froes, R. C., Tolentino, M. A. \& Santos, M. G. dos (2011). Recursos Financeiros do Pronaf: Um Estudo do Planejamento e Controle Realizados pelos Agricultores Familiares das Associações Comunitárias do Vale do Bananal. In Anais do $X X X V$ Encontro da ANPAD. Rio de Janeiro: ANPAD.

SiLVA, E. H. F. M. DA \& BERNARDES, E. M. (2014). Estrutura lógica como metodologia para avaliação de políticas públicas: Uma análise do Pronaf. Revista de Administração Pública, 48 (3), 721-743.

SiLva, E. R. A. DA (1999). Programa Nacional de Fortalecimento da Agricultura Familiar: Relatório técnico das ações desenvolvidas no período 1995/1998. Texto para Discussão, 5-46.

Tomei, P. A. \& SouzA, D. A. A. L. A. (2014). Análise das barreiras que dificultam a transformação do agricultor familiar em empreendedor rural no contexto brasileiro. Revista Ibero-Americana de Estratégia, 13 (3), 107-122.

Troian, A. \& Machado, E. T. L. (2020). O Programa Nacional de Fortalecimento da Agricultura Familiar no Brasil: Análise da evolução e distribuição entre 1999 e 2017. Desenvolvimento em Questão, 18 (50), 109-128. 
Whoqol, Division of Mental Health and Prevention of Substance Abuse (1997). WHOQOL: Measuring Quality of Life. World Health Organization. https://apps.who.int/iris/handle/10665/63482

WHOQOL GROUP (1994). The Development of the World Health Organization Quality of Life Assessment Instrument (the WHOQOL). In J. ORLEY \& W. KUYKEN (Eds.), Quality of Life Assessment: International Perspectives (pp. 41-60). Heidelberg: Springer.

ZANI, F. B. \& CostA, F. L DA (2014). Avaliação da implementação do Programa Nacional de Fortalecimento da Agricultura Familiar: Novas perspectivas de análise. Revista de Administração Pública, 48 (4), 889-912. 


\section{APÊNDICE A}

Procedimento para cálculo dos domínios da escala de qualidade de vida e de bem-estar financeiro, conforme Harper e Power (2013)

\begin{tabular}{|c|c|}
\hline Etapa & Sintaxe SPSS \\
\hline $\begin{array}{l}\text { Verificar se todos os itens foram } \\
\text { preenchidos com respostas entre } 1 \text { e } 5\end{array}$ & $\begin{array}{l}\text { RECODE Q1, Q,2 Q3, Q4, Q5, Q6, Q7, Q8, Q9, Q10, Q11, Q12, Q13, Q14, Q15, } \\
\text { Q16, Q17, Q18, Q19, Q20, Q21, Q22 Q23, Q24, Q25, Q26, Q27, Q28, Q29, Q30, } \\
\text { Q31, Q32, Q33, Q34, Q35, Q36, (1= 1) }(2=2)(3=3)(4=4)(5=5)(E L S E= \\
\text { SYSMIS) }\end{array}$ \\
\hline Converter as questões invertidas & RECODE Q3 Q4 Q26 Q28 Q29 Q36 $(1=5)(2=4)(3=3)(4=2)(5=1)$ \\
\hline \multirow[t]{5}{*}{ Calcular os escores dos domínios } & COMPUTE FISICO = MEAN $(Q 3, Q 4, Q 10, Q 15, Q 16, Q 17, Q 18)^{\star} 4$ \\
\hline & COMPUTE PSICOLOGICO = MEAN $(Q 5, Q 6, Q 7, Q 11, Q 19, Q 26)^{\star} 4$ \\
\hline & COMPUTE SOCIAL $=$ MEAN $(Q 20, Q 21, Q 22) \star 4$ \\
\hline & COMPUTE AMBIENTAL = MEAN $(Q 8, Q 9, Q 12, Q 13, Q 14, Q 23, Q 24, Q 25)^{\star} 4$ \\
\hline & COMPUTE BEF = MEAN $(\mathrm{Q} 27, \mathrm{Q} 28, \mathrm{Q} 29, \mathrm{Q30}, \mathrm{Q31}, \mathrm{Q} 32, \mathrm{Q33}, \mathrm{Q34}, \mathrm{Q35}, \mathrm{Q36})^{\star} 4$ \\
\hline Transformar os escores & COMPUTE FISCO $=(\mathrm{FISICO}-4)^{\star}(100 / 16)$ \\
\hline \multirow[t]{4}{*}{ para uma escala de 0 a 100} & COMPUTE PSICOLOGICO = $\left(\right.$ PSICOLOGICO-4) ${ }^{\star}(100 / 16)$ \\
\hline & COMPUTE SOCIAL $=\left(\right.$ SOCIAL-4) ${ }^{\star}(100 / 16)$ \\
\hline & COMPUTE AMBIENTAL $=(\text { AMBIENTAL-4) })^{\star}(100 / 16)$ \\
\hline & COMPUTE BEF $=(B E F-4)^{\star}(100 / 16)$ \\
\hline Excluir os respondentes cujo número & COUNT TOTAL = Q1 TO Q26 (1THRU 5) \\
\hline de itens não respondidos excedem & SELECT IF (TOTAL>=21) \\
\hline $20 \%$ do total de itens & EXECUTE \\
\hline
\end{tabular}

Fonte: elaborado pelas autoras (2020). 